\title{
Correlation between ABCB1 gene polymorphisms, antiepileptic drug concentrations and treatment response
}

\author{
Octavia Sabin ${ }^{1}$, Ioana Corina Bocşan ${ }^{1 *}$, Adrian Trifa ${ }^{2}$, Zoltan Zsigmond Major ${ }^{1}$, \\ Simona Codruta Heghes ${ }^{3}$, Emanuela Brusturean Bota ${ }^{4}$, Anca Dana Buzoianu ${ }^{1}$ \\ 1. Department of Pharmacology, Toxicology and Clinical Pharmacology, "Iuliu Hatieganu” University \\ of Medicine and Pharmacy \\ 2. Department of Genetics, "Iuliu Hatieganu” University of Medicine and Pharmacy \\ 3. Department of Drug analysis, "Iuliu Hatieganu” University of Medicine and Pharmacy \\ 4. Department of Neurology, Cluj Napoca City Hospital
}

\begin{abstract}
Aim: A possible molecular mechanism of clinically defined multidrug-resistant epilepsy involves drug efflux transporters such as P glycoprotein (P-gp), a member of the ATP-binding cassette subfamily B1 (ABCB1). We have investigated the prevalence of the C3435T, G 2677T/A, and T129C single-nucleotide polymorphisms in the promoter region of MDR1 gene, in Romanian epileptic patients. Methods: 70 epileptic patients evaluated in the Neurology Department of Cluj County Hospital were included in the study. The response to treatment was assessed by reviewing the seizure diaries and the patients were classified as responders or non-responders. Antiepileptic drug (AED) plasmatic concentrations were measured and the patients were divided into 2 groups: first group with AED concentrations in therapeutic range and the second one with sub-optimal AED concentrations. Genotyping the DNA samples, we investigated MDR1 gene polymorphism by polymerase chain reaction (PCR). Results were expressed as genotype and allele frequencies per response group and compared between subgroups. Results: 33 patients (47.14\%) were classified as responders, while the remaining 37 patients (52.86\%) were classified as non-responders. A comparison of responders and non-responders revealed no significant difference in genotype frequency for any of the three mutations studied. The CT heterozygote for ABCB1 T129C had significantly lower AED concentrations ( $p=0.041$ ), with no significant difference for the other polymorphisms studied.

Conclusions: In our study we found an association of CT variant in ABCB1 C129T with lower AED plasmatic concentrations and no association between $A B C B 1$ variants and the drug responsiveness.
\end{abstract}

Keywords: MDR1, antiepileptic drugs, polymorphism, non-responders, P-glycoprotein.

Received: $3^{\text {rd }}$ November 2017; Accepted: 14 ${ }^{\text {th }}$ March 2018; Published: $4^{\text {th }}$ June 2018

*Corresponding author: Ioana C Bocsan, University of Medicine and Pharmacy Cluj Napoca, Romania E-mail: corinabocsan@yahoo.com 


\section{Introduction}

Epilepsy is a debilitating disorder and a public health concern due to the high percentage of patients with treatment-resistant types of epilepsy, associated with a high mortality rate and debilitating psychological and social consequences $(1,2)$. Recent pharmacology research has lead to the development of new antiepileptic drugs (AED), which now are largely used to treat epilepsy. But in a significant number of patients the medication does not fully control epilepsy; irrespective of the definition criteria used, $1 / 3$ of them have refractory epilepsy (3). Because epilepsy is a heterogeneous condition induced by variable causes $(4,5)$, a reduced response to therapy is influenced by multiple factors, both genetic and environmental (2).

Drug-responsiveness is influenced by multiple factors including the type of seizure, the age, the etiology, early age of seizure onset, structural cerebral abnormalities or brain lesions at genetics. Also, the pharmacokinetics and pharmacodynamics of AEDs may rely on genetic or acquired factors (6). One of the challenges in epilepsy treatment is to predict which patients will develop drug resistance (7).

Experts have advanced several hypotheses to explain the causes of resistance to AED (2). The two main theories of multi-resistance are 1) changes in the drug target and 2) changes in the efflux protein function. The first hypothesis is based on studies suggesting that certain structural changes (8) or abnormalities of the brain network, which also involved neurotransmitter dysfunction (9) in epileptic patients may constitute causes of resistance to AED therapy, i.e. the condition is determined by a change in the drug target. The second hypothesis was based on the finding that one of the main obstacles in the treatment of neurological conditions, including epilepsy, is the poor penetration across the blood-brain barrier (BBB). New published data suggest that a possible molecular mechanism of multidrug resistance epilepsy involves drug efflux transporters such as the ATP-binding cassette subfamily B member $1, \mathrm{ABCB} 1$, also known as MDR1 or P glycoprotein (P-gp) $(10-12)$. P-gp is a protein encoded in humans by 2 genes that belong to the same family, ABCB1 (known as MDR1) and ABCB4 (MDR2), located on chromosome 7 (7q21). The ATP-dependent drug transporter proteins and P-glycoprotein (P-gp) are involved in drug efflux from different cells, reducing drug accumulation (13). P-gp is a substrate for several antiepileptic drugs, such as phenytoin or carbamazepine. The identification of MDR1 gene mutations, which encode P-gp, could represent a predictive factor for therapeutic goals and could be exploited to improve therapeutic response. Studies have shown a low plasma level of carbamazepine and phenytoin in patients with intestinal MDR1 gene overexpression; in these cases, genetic polymorphisms at positions 3435 and 2677 have influenced the used doses of antiepileptics $(14,15)$. Low drug plasma levels could be correlated with treatment failure. Although the silent polymorphisms of $\mathrm{ABCB} 1$ gene might not be the only cause of resistance, there is evidence that they could influence the activity of P-gp and they could be a valuable marker to predict who will develop resistance to AED. Thus, these polymorphisms could be associated with drug-resistant forms of epilepsy.

In the present study we aimed to evaluate the influence of some ABCB1 gene polymorphisms on AED plasmatic concentration and treatment response in epileptic patients.

\section{Material and method}

\section{Patients}

An initial group of 100 epileptic patients admitted to the Neurology Department of Cluj-Napoca County Hospital were included in this 
study. Seventy patients, who met the criteria described below, were enrolled in the final surveillance. Specific exclusion criteria were major psychiatric disease, history of alcohol abuse, uncontrolled kidney or liver diseases, and evidence of noncompliance with medication.

The patients were evaluated based to international guidelines criteria and the type of epilepsy was established. The response to treatment was assessed by reviewing the clinical notes (at least 4 visits in one year) and seizure diaries. The response to treatment was assessed after 1 year, according to the guidelines of the International League Against Epilepsy (ILAE) (16). Patients who were seizure-free for at least 12 months on their current antiepileptic regimen were classified as responders. Those who had continued to experience seizures in the last 12 months of follow-up despite prior exposure to a minimum of two appropriate antiepileptic regimens (mono-therapy or poly-therapy) at maximally tolerated doses were considered to be non-responders. Patients with undetermined and undefined forms of epilepsy according to ILAE definitions, or cases with wrong or inappropriate drug selection or low compliance to medication were excluded from this study.

The study protocol is in accordance with the Declaration of Helsinki. The study was approved by the Ethical Committee of the University of Medicine and Pharmacy Cluj Napoca, and each patient signed an informed consent before inclusion.

\section{AED plasmatic concentrations}

For all patients, steady-state plasmatic concentrations of AED were determined, after a minimum one month of continuous treatment. Peripheral blood samples were drawn from each patient à jeun, before medication. AED plasmatic concentrations were measured for valproate, phenytoin, phenobarbital, carbamazepine, oxcarbazepine, lamotrigine, and topiramate by a modified GC-FID protocols (17). The patients were divided into 2 groups: first group included patients with AED concentrations in therapeutic range (see table 1) and the second one patients with sub-optimal AED concentrations according to the ILAE guideline (18).

\section{Genotyping}

ABCB1 polymorphisms were determinated using DNA extracted from lymphocytes of peripheral blood, using commercial kits for genomic DNA extraction (Wizzard Genomic DNA Purification Kit, Promega, USA). Genotyping was performed by PCR-RFLP technique according to previously described protocols $(18,19)$. The used sequences of primers are shown in Table 2 . We analyzed the resulted fragments after digestion in $2.2 \%$ agarose gel and visualization using a photo documentation and gel analysis system (Vilber Lourmat Imaging System ${ }^{\circledR}$ ).

\section{Statistical analysis}

The statistical evaluation was performed using SPSS version 17. The relationship between various genotypes, alleles and responsiveness was examined using the Pearson $\chi 2$-test or Fisher's exact test, according to expected counts (less than 5 for Fisher's test). Statistical significance was accepted at $p<0.05$.

Table 1. Plasmatic therapeutic ranges of the antiepileptic drugs (17)

\begin{tabular}{lc}
\hline AED & Reference range $(\mathbf{m g} / \mathbf{L})$ \\
\hline Carbamazepine & $4-12$ \\
\hline Lamotrigine & $2.5-15$ \\
\hline Oxcarbazepine & $3-35$ \\
\hline Phenobarbital & $10-40$ \\
\hline Phenytoin & $10-20$ \\
\hline Topiramate & $5-20$ \\
\hline Valproic acid & $50-100$ \\
\hline
\end{tabular}


Table 2. Primers used to determine ABCB1 polymorphisms

\begin{tabular}{lc}
\hline Polymorphism & Primer \\
\hline \multirow{2}{*}{ C3435T } & Fw 5'-TTGATG GCAAAGAAA TAAAGC-3'; \\
& Rev 5'-CTTACATTAGGCAGT GAC TCG-3' \\
\hline \multirow{2}{*}{ G2677A/T } & Fw 5'-TTT GCAGGC TAT AGG TTC CAG-3' \\
& Rev G2677A, 5'-GTT TGA CTC ACC TTC CCA G-3'; \\
\hline \multirow{2}{*}{ T-129C } & Rev G2677T 5'-TTTAGTTTGACTCACCTTCCCG-3' \\
& Fw 5'-TCAGCA TTC AGT CAA TCC GG-3'; \\
& Rev 5'-TTT GCG TGC CCC TAC CTC-3' \\
\hline
\end{tabular}

\section{Results}

Seventy epilepsy patients (31 men, 39 women), aged between 18 and 75 (mean age 36 years) were included. Characteristics of epileptic patients are presented in table 3 . There were no differences between male and female patients regarding response to treatment $(\mathrm{p}=0.853)$, type of epilepsy (idiopathic vs. secondary epilepsy, $\mathrm{p}=0.395$ ) or plasmatic level of AED (therapeutic AED concentration vs. sub-therapeutic AED concentration, $\mathrm{p}=0.165$ ). Thirteen patients $(18.6 \%)$ had sub-therapeutic AED concentrations.

The frequencies of determined ABCB1 genotypes are shown in tables 4 and 5 .

Each genotype frequency was consistent with Hardy-Weinberg equilibrium, and was sim- ilar to those of patients with epilepsy and healthy controls in the previous studies done in the Romanian population (19-21). All studied ABCB1 (MDR1) polymorphisms followed Hardy-Weinberg equilibrium with no difference between responders and non-responders or therapeutic vs. sub-therapeutic group.

For the ABCB1 C3435T polymorphisms, three genotypes were identified: $\mathrm{CC}, \mathrm{CT}$, and TT. For ABCB1 T129C, no mutant homozygote $\mathrm{CC}$ was found in the studied population. For G2677T/A, five of six possible genotypes (GG, GT, TT, TA, GA) were identified. The AA mutant variant of ABCB1 G2677T/A was not found in our epileptic population.

Of the three candidate SNPs, ABCB1 T129C showed a significant association with the

Table 3. Characteristics of epileptic patients

\begin{tabular}{lccc}
\hline & $\begin{array}{c}\text { Female } \\
\mathbf{N = 3 9}\end{array}$ & $\begin{array}{c}\text { Male } \\
\mathbf{N = 3 1}\end{array}$ & $\begin{array}{c}\text { All } \\
\mathbf{N}=\mathbf{7 0}(\boldsymbol{\%})\end{array}$ \\
\hline Age, mean (std. deviation) & $35.1(13.086)$ & $37.29(13.031)$ & $36.07(13.013)$ \\
\hline Type of epilepsy N, (\%) & & \\
\hline Idiopathic & $22(56.4)$ & $20(64.5)$ & $42(60)$ \\
\hline Secondary & $17(43.6)$ & $11(34.5)$ & $28(40)$ \\
\hline Response N, (\%) & & $15(48.4)$ & $33(47.1)$ \\
\hline Responders & $18(46.2)$ & $16(51.6)$ & $37(52.9)$ \\
\hline Non-responders & $21(53.8)$ & & $11(15.7)$ \\
\hline AED concentration $\mathbf{N},(\%)$ & $6(15.4)$ & $5(16.4)$ & $59(84.3)$ \\
\hline Sub-therapeutic & $33(84.6)$ & $26(83.9)$ & \\
\hline Therapeutic & & & \\
\hline
\end{tabular}


Table 4. ABCB1 genotypes frequencies at responders and non responders

\begin{tabular}{|c|c|c|c|c|c|}
\hline \multirow{2}{*}{$\begin{array}{l}\text { ABCB1 } \\
\text { genotype }\end{array}$} & & \multicolumn{3}{|c|}{$\begin{array}{c}\text { Response } \\
\text { Genotype frequency, N (\%) }\end{array}$} & \multirow{2}{*}{ p value } \\
\hline & & $\begin{array}{l}\text { Responder } \\
\mathbf{N}=\mathbf{3 3}\end{array}$ & $\begin{array}{c}\text { Non-responder } \\
\mathbf{N}=\mathbf{3 7}\end{array}$ & $\begin{array}{r}\text { Total } \\
\mathbf{N}=\mathbf{7 0}\end{array}$ & \\
\hline \multirow{3}{*}{ C3435T } & $\mathrm{CC}$ & $6(18.18 \%)$ & $8(21.6 \%)$ & $14(20 \%)$ & \multirow{3}{*}{0.922} \\
\hline & CT & $18(54.55 \%)$ & $20(54.1 \%)$ & $38(54.28 \%)$ & \\
\hline & TT & $9(27.27 \%)$ & $9(24.3 \%)$ & $18(25.72 \%)$ & \\
\hline \multirow{3}{*}{ T129C } & TT & $31(93.93 \%)$ & $34(91.89 \%)$ & $65(92.85 \%)$ & \multirow{3}{*}{0.74} \\
\hline & CT & $2(6.06 \%)$ & $3(8.11 \%)$ & $5(7.15 \%)$ & \\
\hline & $\mathrm{CC}$ & $0(0 \%)$ & $0(0 \%)$ & $0(0 \%)$ & \\
\hline \multirow{6}{*}{ G2677T/A } & GG & $11(33.3 \%)$ & $12(32.4 \%)$ & $23(32.9 \%)$ & \multirow{6}{*}{0.678} \\
\hline & GT & $14(42.4 \%)$ & $19(51.4 \%)$ & $33(47.1 \%)$ & \\
\hline & TT & $6(18.2 \%)$ & $4(10.8 \%)$ & $10(14.3 \%)$ & \\
\hline & GA & $0(0 \%)$ & $1(2.7 \%)$ & $1(1.4 \%)$ & \\
\hline & $\mathrm{TA}$ & $2(6.1 \%)$ & $1(2.7 \%)$ & $3(4.3 \%)$ & \\
\hline & AA & $0(0 \%)$ & $0(0 \%)$ & $0(0 \%)$ & \\
\hline
\end{tabular}

sub-therapeutic plasmatic concentration. Compared with TT wild variant, the CT heterozygote had a higher frequency of low AED concentra- tion $(\mathrm{p}=0.041)$. For patients with secondary epilepsy, we observed an increased frequency of patients with sub-therapeutic concentrations for

Table 5. ABCB1 genotype and plasmatic concentrations

\begin{tabular}{|c|c|c|c|c|c|}
\hline \multirow{2}{*}{\multicolumn{2}{|c|}{ Genotype }} & \multicolumn{3}{|c|}{$\begin{array}{c}\text { AED concentrations } \\
\text { Genotype frequency, } \mathbf{N}(\%)\end{array}$} & \multirow{2}{*}{$\begin{array}{c}\text { Statistical } \\
\text { Analysis } \\
\text { p value }\end{array}$} \\
\hline & & $\begin{array}{l}\text { Sub therapeutic } \\
\qquad \mathbf{N}=\mathbf{1 3}\end{array}$ & $\begin{array}{l}\text { In range } \\
\mathbf{N}=\mathbf{5 7}\end{array}$ & $\begin{array}{l}\text { Total } \\
\mathbf{N}=\mathbf{7 0}\end{array}$ & \\
\hline \multirow{3}{*}{ C3435T } & $\mathrm{CC}$ & $4(30.8 \%)$ & $10(17.5 \%)$ & $14(20 \%)$ & \multirow{3}{*}{0.452} \\
\hline & $\mathrm{CT}$ & $7(53.8 \%)$ & $31(54.4 \%)$ & $38(54.28 \%)$ & \\
\hline & $\mathrm{TT}$ & $2(15.4 \%)$ & $16(28.1 \%)$ & $18(25.72 \%)$ & \\
\hline \multirow{6}{*}{ G2677T/A } & GG & $5(38.5 \%)$ & $17(29.8 \%)$ & $22(31.4 \%)$ & \multirow{6}{*}{0.694} \\
\hline & GT & $5(38.8 \%)$ & $27(47.4 \%)$ & $32(45.7 \%)$ & \\
\hline & $\mathrm{TT}$ & $2(15.4 \%)$ & $10(17.5 \%)$ & $12(17.1 \%)$ & \\
\hline & GA & $1(7.7 \%)$ & $1(1.8 \%)$ & $2(2.9 \%)$ & \\
\hline & TA & $0(0 \%)$ & $2(3.5 \%)$ & $2(2.9 \%)$ & \\
\hline & AA & $0(0 \%)$ & $0(0 \%)$ & $0(0 \%)$ & \\
\hline \multirow{3}{*}{ T129C } & $\mathrm{TT}$ & $10(76.9 \%)$ & $55(96.5 \%)$ & $65(92.85 \%)$ & \multirow{3}{*}{0.041} \\
\hline & $\mathrm{CT}$ & $3(23.1 \%)$ & $2(3.5 \%)$ & $5(7.15 \%)$ & \\
\hline & $\mathrm{CC}$ & $0(0 \%)$ & $0(0 \%)$ & $0(0 \%)$ & \\
\hline
\end{tabular}


heterozygous 129TC ( $\mathrm{p}=0.086)$, but this difference did not reach the level of statistical significance. This trend was not observed in the other studied polymorphisms.

There were no significant differences between responders and non-responders regarding genotypes and allele frequencies for all studied SNPs. A subgroup analysis of patients with idiopathic or secondary epilepsy was similarly unremarkable. Regarding response to treatment in the subgroup of patients with idiopathic epilepsy, 21 patients were considered responders, while 21 of them were non-responders. In patients with secondary epilepsy, 12 patients were responders, while 16 patients were non-responders $(\mathrm{p}=0,344)$. Among patients with idiopathic epilepsy, 9 of them had sub-therapeutic AED concentrations and 33 therapeutic levels. In the second group of patients with secondary epilepsy, 4 patients presented sub-therapeutic AED concentrations and 24 therapeutic AED concentrations $(p=0,567)$.

\section{Discussion}

This study demonstrated that the ABCB1 T129C polymorphism, CT genotype in promoter region was significantly associated with lower AED concentrations, but had no influence over refractory epilepsy in Romanian patients. We did not observe any correlations between ABCB1 C3435T, G2677T/A polymorphisms and AED concentrations and treatment outcome in our cohort.

It is essential to perform a complete assessment of all the factors influencing therapeutic response, to promote early prediction based on these factors, the probability of an unsatisfactory response, to ensure faster advanced intervention (i.e. surgical therapy) (6), as well as an assessment of the methods to influence these factors.

The P-gp mediated drug resistance is characterized by a reduction in transport of different compounds from blood to brain (22). The inves- tigated antiepileptic drugs in the present study are P-gp substrates (23) and each one could be effluxed out from the brain by this mechanism. The overexpression of P-gp augments this process and some of the MDR1 genetic variants may be associated with P-gp over-expression $(24,25)$.

The first study on $\mathrm{ABCB} 1$ polymorphism in epilepsy demonstrated that patients with drug-resistant epilepsy presented the CC genotype more frequently and a lower frequency of the TT one compared to drug-responsive epileptic patients or non epileptic controls (26). Following this, a series of studies, especially on C3435T mutation were conducted on different populations (27-30) with conflicting results. Our data did not confirm the original report which noted an increased prevalence of the CC genotype in patients with resistant form of epilepsy. The present results are similar with a recently published meta-analysis of 57 case-controlled studies on C3435T, G2677T/A, and C1236T mutation influence over refractory epilepsy (31). In this meta-analysis, no difference between the frequency of observed alleles or genotypes in the population with refractory epilepsy was remarked, except for a significantly decreased risk of low therapeutic response to AEDs in patients who present $\mathrm{T}$ allele of $\mathrm{C} 3435 \mathrm{~T}$ variant in a Caucasian population.

These differences between studies occurred probably due to a different number of patients included in the studies, the different ethnic populations, and the definition criteria of refractory epilepsy. A previous study performed in a Romanian population had showed an association between TT and CT genotypes in 1236 position with drug-responsive forms in children with idiopathic epilepsy (32). In the present, study we did not investigate this polymorphism. In Butila study e TT genotype in position 2677 was more frequently observed in drug-responsive cases (32), which is different from the present data. 
The conflicting results among studies could be explained through different combinations of polymorphisms that are commonly inherited together, so different haplotypes, rather than an SNP may have influence on treatment response. Studying only a few mutations (especially C3435T) ignores the fact that silent mutations may have a significant role in the occurrence of drug resistance, since they may be in linkage imbalance with non-silent SNP. SNP affects the expression and structure of P-gp into the membrane, thereby altering the interaction between substrate and its binding site (25). Also, the drug responsiveness of a patient with epilepsy may be variable in time, it is not a fixed state, because the course of epilepsy sometimes fluctuates (7).

There are a series of studies showing reduced plasma levels of some antiepileptic drugs: carbamazepine (14), oxcarbazepine (33), lamotrigine $(34,35)$, phenobarbital (35), phenytoin $(15,36)$, valproic acid $(21,37)$, in association with ABCB1 polymorphisms. Studies regarding drug pharmacokinetics associated with different SNPs have generally conflicting findings that can be explained by haplotype heterogeneity in different populations. On the other hand, we have to take into account that some AEDs are metabolized by CYP450, so polymorphisms of CYP2C9, CYP2C19 are associated with the metabolism of some specific AEDs but not with others. In the present study, we did not analyze the association between MDR1 and CYP450 polymorphisms and drug-resistance in patients treated with a specific AED. Polymorphisms of enzymes affecting AED metabolism may have an influence on serum concentrations of AEDs and produce insufficient concentrations of AED in the brain, which may contribute to a low therapeutic response.

In our study we noticed that the frequency of patients who do not reach therapeutic AED concentrations is reduced compared with the fre- quency of non-responsive patients, and this observation could be an argument in favor of other mechanisms of resistance.

For ABCB1 T129C, the frequency of mutant variants is very low in the general population, less that $5 \%$ for CT or even lower in some Asian populations, so it has been less studied. This is the first study done in epilepsy for this polymorphism.

In our study, due to the fact that no values of $p$ were found to be lower than 0.25 , except the one already discussed, a logistic regression to determine the role of each genotype on pharmaco-resistance was considered futile. Also, analyzing the haplotype based on above three single nucleotides was not necessary for the same reason. In the study by Sanchez, there was a significant association of drug-resistance with covariates, including the type of seizures and etiology of epilepsy. But after adjustment by clinical factors through a logistic regression, a significant association between the SNPs studied and drug-resistance was not found (6). Because we did not apply the logistic regression for the aforementioned reasons, we cannot conclude if there is an association between types of epilepsy and MDR polymorphisms.

The study has some limitations. First, the present study did not explore the correlation between the candidate SNPs and all available AEDs, limiting the number of patients studied. The sample size was not large enough. The validation of results requires research continuity and a larger sample of patients, to ensure statistical analysis reliability. A more extensive study of ABCB1 mutation and the haplotypes could determine different results.

\section{Conclusion}

In our study, we found an association of CT variant in $\mathrm{ABCB} 1 \mathrm{C} 129 \mathrm{~T}$ with lower AED plas- 
matic concentrations and no association between $\mathrm{ABCB} 1$ variants and drug responsiveness.

\section{Acknowledgements}

This study was supported by the Research Grant no. 41-082/2007 - FARMACYP - from the National Center for Programs Management, Romanian Ministry of Education and Research.

\section{References}

1. Kwan P. The natural history of epilepsy: an epidemiological view. J Neurol Neurosurg Psychiatry. 2004 Oct;75(10):1376-81. DOI: 10.1136/jnnp.2004.045690

2. Tang F, Hartz AMS, Bauer B. Drug-resistant epilepsy: Multiple hypotheses, few answers. Vol. 8, Frontiers in Neurology. Frontiers Media SA; 2017. p. 301.

3. Kwan P, Brodie MJ. Refractory epilepsy: a progressive, intractable but preventable condition? Seizure. 2002 Mar;11(2):77-84. DOI: 10.1053/seiz.2002.0593

4. Fisher RS, Cross JH, French JA, Higurashi N, Hirsch E, Jansen FE, et al. Operational classification of seizure types by the International League Against Epilepsy: Position Paper of the ILAE Commission for Classification and Terminology. Epilepsia. 2017 Apr 1;58(4):522-30. DOI: 10.1111/epi.13670

5. Berg A, Scheffer I. New concepts in classification of the epilepsies: Entering the 21st century - Berg - 2011 Epilepsia - Wiley Online Library. Epilepsia. 2011.

6. Sánchez MB, Herranz JL, Leno C, Arteaga R, Oterino A, Valdizán EM, et al. Genetic factors associated with drug-resistance of epilepsy: relevance of stratification by patient age and aetiology of epilepsy. Seizure. 2010 Mar 1;19(2):93-101. DOI: 10.1016/j.seizure.2009.12.004

7. Berg AT. Identification of Pharmacoresistant Epilepsy. Vol. 27, Neurologic Clinics. 2009. p. 1003-13. DOI: 10.1016/j.ncl.2009.06.001

8. Semah F, Picot M, Adam C, Broglin D, Arzimanoglou A, Bazin B, et al. Is the underlying cause of epilepsy a major prognostic factor for recurrence? Neurology. 1998;51:1256-62. DOI: 10.1212/WNL.51.5.1256

9. Proper E a, Hoogland G, Kappen SM, Jansen GH, Rensen MG a, Schrama LH, et al. Distribution of glutamate transporters in the hippocampus of patients with pharmaco-resistant temporal lobe epilepsy. Brain. 2002;125(Pt 1):32-43.

10. Dombrowski SM, Desai SY, Marroni M, Cucullo L, Goodrich K, Bingaman W, et al. Overexpression of multiple drug resistance genes in endothelial cells from patients with refractory epilepsy. Epilepsia. 2001;42(12):15016. DOI: $10.1046 / \mathrm{j} .1528-1157.2001 .12301 . \mathrm{x}$
11. Hartz AMS, Pekcec A, Soldner ELB, Zhong Y, Schlichtiger J, Bauer B. P-gp Protein Expression and Transport Activity in Rodent Seizure Models and $\mathrm{Hu}-$ man Epilepsy. Mol Pharm. 2017 Apr;14(4):999-1011. DOI: 10.1021/acs.molpharmaceut.6b00770

12. Feldmann M, Asselin M-C, Liu J, Wang S, McMahon A, Anton-Rodriguez J, et al. P-glycoprotein expression and function in patients with temporal lobe epilepsy: a case-control study. Lancet Neurol. 2013 Aug;12(8):77785. DOI: 10.1016/S1474-4422(13)70109-1

13. Mahringer A, Fricker G. ABC transporters at the blood-brain barrier. Expert Opin Drug Metab Toxicol. 2016;12(5):499-508. DOI: $10.1517 / 17425255.2016 .1168804$

14. Simon C, Stieger B, Kullak-Ublick GA, Fried M, Mueller S, Fritschy JM, et al. Intestinal expression of cytochrome P450 enzymes and ABC transporters and carbamazepine and phenytoin disposition. Acta Neurol Scand. 2007;115(4):232-42. DOI: 10.1111/j.16000404.2006.00761.x

15. Kerb R, Aynacioglu a S, Brockmöller J, Schlagenhaufer R, Bauer S, Szekeres T, et al. The predictive value of MDR1, CYP2C9, and CYP2C19 polymorphisms for phenytoin plasma levels. Pharmacogenomics J. 2001;1(3):204-10. DOI: 10.1038/sj.tpj.6500025

16. Kwan P, Arzimanoglou A, Berg AT, Brodie MJ, Allen Hauser W, Mathern G, et al. Definition of drug resistant epilepsy: Consensus proposal by the ad hoc Task Force of the ILAE Commission on Therapeutic Strategies. Epilepsia. 2009 Nov;51(6):1069-77. DOI: 10.1111/j.1528-1167.2009.02397.x

17. Volmut J, Matisová E, Ha PT. Simultaneous determination of six antiepileptic drugs by capillary gas chromatography. J Chromatogr B Biomed Sci Appl. 1990;527(C). DOI: 10.1016/S0378-4347(00)82127-1

18. Patsalos PN, Berry DJ, Bourgeois BFD, Cloyd JC, Glauser TA, Johannessen SI, et al. Antiepileptic drugs - Best practice guidelines for therapeutic drug monitoring: A position paper by the subcommission on therapeutic drug monitoring, ILAE Commission on Therapeutic Strategies. Epilepsia. 2008;49(7):1239-76. DOI: 10.1111/j.1528-1167.2008.01561.x

19. Buzoianu AD, Bocsan IC, Maier C, Trifa AP, Popp RA, Dumbrava LP, et al. Genotype-pheno type corelations between the aleles of the MDR1 C3435T polymorphism and pharmacokinetic parameters in Romanian epileptic patients. Ther Pharmacol Clin Toxicol. 2011;15(1):40-4.

20. Trifa AP, Popp RA, Militaru MS, Crisan TO, Farcas MF, Csernik FA, et al. The $\mathrm{C}$ and $\mathrm{T}$ alleles of the MDR1 (Multiple Drug Resistance 1) C3435T polymorphism share similar frequencies in the Romanian population. Ann RSCB. 2009; XIV(1):68-72.

21. Sabin O, Pop R, Trifa A, Buzoianu AD. The influence of CYP2C9, CYP2C19 and ABCB1 polymorphisms on 
the plasma concentrations of valproic acid in epileptic patients. Hum Vet Med. 2016;8(1):29-33.

22. Löscher W, Potschka H. Role of drug efflux transporters in the brain for drug disposition and treatment of brain diseases. Prog Neurobiol. 2005;76(1):22-76. DOI: 10.1016/j.pneurobio.2005.04.006

23. Lai Y. Transporters in drug discovery and development : detailed concepts and best practice. Elsevier Science; 2013. 159-174 p. DOI: 10.1002/9781118354483

24. Mosyagin I, Runge U, Schroeder HW, Dazert E, Vogelgesang S, Siegmund W, et al. Association of ABCB1 genetic variants $3435 \mathrm{C}>\mathrm{T}$ and $2677 \mathrm{G}>\mathrm{T}$ to $\mathrm{ABCB} 1$ mRNA and protein expression in brain tissue from refractory epilepsy patients. Prism. 2008;49(9):1555-61. DOI: $10.1111 / \mathrm{j} .1528-1167.2008 .01661 . x$

25. Kimchi-Sarfaty C, Oh JM, Kim I-W, Sauna ZE, Calcagno AM, Ambudkar S V., et al. A "Silent" Polymorphism in the MDR1 Gene Changes Substrate Specificity. Science (80- ). 2007;315(5811):525-8. DOI: $10.1126 /$ science. 1135308

26. Siddiqui A, Kerb R, Weale ME, Brinkmann U, Smith A, Goldstein DB, et al. Association of multidrug resistance in epilepsy with a polymorphism in the drug-transporter gene ABCB1. N Engl J Med. 2003;348(15):1442-8. DOI: 10.1056/NEJMoa021986

27. Hung C-C, Tai JJ, Lin C-J, Lee M-J, Liou H-H. Complex haplotypic effects of the ABCB1 gene on epilepsy treatment response. Pharmacogenomics. 2005;6(4):411-7. DOI: $10.1517 / 14622416.6 .4 .411$

28. Kim YO, Kim MK, Woo YJ, Lee MC, Kim JH, Park $\mathrm{KW}$, et al. Single nucleotide polymorphisms in the multidrug resistance 1 gene in Korean epileptics. Seizure. 2006;15(1):67-72. DOI: 10.1016/j.seizure.2005.11.001

29. Sills GJ, Mohanraj R, Butler E, McCrindle S, Collier L, Wilson EA, et al. Lack of association between the C3435T polymorphism in the human multidrug resistance (MDR1) gene and response to antiepileptic drug treatment. Epilepsia. 2005;46(5):643-7. DOI: 10.1111/j.1528-1167.2005.46304.x

30. Haerian BS, Lim KS, Mohamed EHM, Tan HJ, Tan CT,
Raymond AA, et al. Lack of association of ABCB1 and PXR polymorphisms with response to treatment in epilepsy. Seizure. 2011 Jun;20(5):387-94. DOI: 10.1016/j. seizure.2011.01.008

31. Li H, Wang B, Chang C, Wu M, Xu Y, Jiang Y. The roles of variants in human Multidrug Resistance (MDR1) gene and their haplotypes on antiepileptic drugs response: A meta-analysis of 57 studies. PLoS One. 2015;10(3):e0122043. DOI: 10.1371/journal. pone. 0122043

32. Butila AT, Sin A, Szabo ER, Micheu C, Moldovan VG, Voidazan S, et al. ABCB1 gene polymorphisms is not associated with drug-resistant epilepsy in Romanian children. Rev Rom Med Lab. 2015;23(4):469-82. DOI: 10.1515/rrlm-2015-0037

33. Shen C, Zhang B, Liu Z, Tang Y, Zhang Y, Wang S, et al. Effects of ABCB1, ABCC2, UGT2B7 and HN$\mathrm{F} 4 \alpha$ genetic polymorphisms on oxcarbazepine concentrations and therapeutic efficacy in patients with epilepsy. Seizure. 2017;51:102-6. DOI: 10.1016/j.seizure.2017.07.015

34. Lovrić M, Božina N, Hajnšek S, Kuzman MR, Sporiš $\mathrm{D}$, Lalić Z, et al. Association between lamotrigine concentrations and $\mathrm{ABCB} 1$ polymorphisms in patients with epilepsy. Ther Drug Monit. 2012 Oct;34(5):51825. DOI: $10.1097 /$ FTD.0b013e31826517c6

35. Zhou Y, Wang X, Li H, Zhang J, Chen Z, Xie W, et al. Polymorphisms of ABCG2, ABCB1 and $\mathrm{HNF} 4 \alpha$ are associated with Lamotrigine trough concentrations in epilepsy patients. Drug Metab Pharmacokinet. 2015 Aug;30(4):282-7. DOI: 10.1016/j.dmpk.2015.05.002

36. Wang P, Yin T, Ma HY, Liu DQ, Sheng YH, Wang C, et al. Effects of CYP3A4/5 and ABCB1 genetic polymorphisms on carbamazepine metabolism and transport in Chinese patients with epilepsy treated with carbamazepine in monotherapy and bitherapy. Epilepsy Res. 2015 Nov;117:52-7. DOI: 10.1016/j.eplepsyres.2015.09.001

37. Zhu MM, Li HL, Shi LH, Chen XP, Luo J, Zhang ZL. The pharmacogenomics of valproic acid. J Hum Genet. 2017 Dec;62(12):1009-14. DOI: 10.1038/jhg.2017.91 